\title{
Protection Against Pathogen and Salt Stress by Four Plant Growth-Promoting Rhizobacteria Isolated from Pinus sp. on Arabidopsis thaliana
}

\author{
J. Barriuso, B. Ramos Solano, and F. J. Gutiérrez Mañero
}

Universidad San Pablo CEU. Facultad de Farmacia. P.O. Box 67, Boadilla del Monte, 28668, Madrid, Spain. Accepted for publication 21 January 2008.

\begin{abstract}
Barriuso, J., Ramos Solano, B., and Gutiérrez Mañero, F. J. 2008. Protection against pathogen and salt stress by four plant growth-promoting rhizobacteria isolated from Pinus sp. on Arabidopsis thaliana. Phytopathology 98:666-672.

The ability of four plant growth-promoting rhizobacteria, isolated in a previous study, to induce systemic resistance on Arabidopsis thaliana Col 0 against biotic and abiotic stress was evaluated. All the bacteria enhanced protection against the foliar pathogen Pseudomonas syringae DC3000 and increased plant tolerance to salt stress $(\mathrm{NaCl} 60 \mathrm{mM})$. Bacillus sp. strain L81 and Arthrobacter oxidans strain BB1 performed best with a decrease in the disease index of 61.2 and $52.3 \%$, respectively, and a reduction in the mortality due to salt stress of 72.4 and $57.8 \%$, respectively.

Additionally, significant differences were found in growth and photosynthesis, again, L81 and BB1 performed best either in normal or under stress conditions. In order to elucidate the pathway elicited by these two strains to induce systemic resistance, experiments with the transgenic line of Arabidopsis thaliana NahG (defective in salicylic acid [SA]) and with the jarl mutant (defective in jasmonic acid) were carried out. Results showed that the SA-dependent pathway was involved in the defense response induced by strains L81 and BB1. Results from quantitative reverse transcription-polymerase chain reaction analysis of the $P R 1$ gene, related to the SA-dependent pathway and the PDF1.2 gene related to the SAindependent pathway, showed an increased expression of $P R 1$ in BB1treated plants, confirming involvement of the SA-dependent pathway in the defensive response.
\end{abstract}

Plant growth-promoting rhizobacteria (PGPR) (17) are nonpathogenic beneficial soil rhizobacteria that play a key role in plant health and nutrition (25). These may benefit plant growth, either by improving plant nutrition or producing plant growth regulators $(11,13)$. They may also prevent attack from pathogenic microorganisms $(3,41)$ or help in the establishment of symbiosis with rhizobia or with mycorrhiza $(9,45)$.

PGPR can be found among different bacterial genera such as Arthrobacter, Chryseobacterium, Curtobacterium, Gluconacetobacter, Azospirillum, Azotobacter, Bacillus, Burkholderia, Herbaspirillum, and Pseudomonas $(3,12,26)$. The mechanisms by which PGPR promote growth have already been widely reported (45), while defensive mechanisms such as induced systemic resistance are currently being intensively investigated from the viewpoint of transduction pathways within plants $(8,41)$.

Plants possess various inducible defense mechanisms to protect themselves against pathogen attacks. A classic example of this is systemic acquired resistance (SAR), which is activated after infection by a necrotizing pathogen. SAR has been demonstrated in many plant species and confers resistance against a broad spectrum of plant pathogens in distant uninfected plant parts (32). Some root colonizing nonpathogenic rhizobacteria may also trigger disease resistance in the host plant, a phenomenon that has been termed induced systemic resistance (ISR) (41). The ISR is a plant mediated mechanism that starts in the roots and extends up to the shoots. It is effective against different types of plant pathogens. The triggering of disease resistance by nonpathogenic bacteria depends on plant species to a different extent. Hence, it is

Corresponding author: J. Barriuso; E-mail address: jbarriuso@ceu.es

doi:10.1094/PHYTO-98-6-0666

(C) 2008 The American Phytopathological Society interesting to find strains that can stimulate a wide array of plants in order to select them for potential commercial uses.

In Arabidopsis thaliana, SAR is associated with local and systemic increases in endogenously synthesized salicylic acid (SA) and a coordinated expression of genes encoding pathogenesis-related proteins (PR) $(23,39)$. SA is a necessary intermediate in the SAR signal transduction pathway because SAnonaccumulating plants (NahG), expressing the bacterial SA hydroxylase gene $N a h G$, and other mutants such as SA-induction deficient (Sid) mutants, encoding a mutated isochorismate synthase necessary for the synthesis of SA, are impaired in SAR $(14,23)$. In contrast, there are some bacteria, for example, Pseudomonas fluorescens WCS417r, that trigger ISR independent of concomitant PR gene activation $(28,29,44,46)$. Furthermore, there are other metabolic responses that consist in a faster and stronger defense expression, which are only appreciated upon pathogen challenge; this phenomenon is called priming, and has been described for nonpathogenic root-colonizing pseudomonads rhizobacterium-mediated induced systemic resistance (5). The JA response mutant jarl and the ethylene response mutant etrl, which both express normal levels of pathogen induced SAR $(22,23,30)$, did not express ISR upon treatment with WCS417r, indicating that the ISR-signaling pathway requires components of the JA and ethylene response $(18,30)$. van Wees et al. (44) also demonstrated that the SAR and ISR pathways are fully compatible, resulting in an additive effect on the level of induced protection.

Nowadays special interest is put on research directed to the development of inoculants with beneficial bacteria (PGPR) for environmentally friendly agricultural management. The main purpose of these biofertilizers is stimulation of the plant's defensive metabolism, which will allow crop cultivation in areas with a high pathogen incidence, or on degraded or saline soils or subject to water restriction conditions. Overcoming these issues is a big problem in modern agriculture due to the lack of fertile soils and 
the need to feed an increasing world population. Several authors $(4,38)$ have related the expression of some genes in the defensive response with genes expressed in salt stress situations, e.g., genes involved in ethylene, JA, and abscisic acid pathways. Because of this, plants induced with the proper biological agent may improve their adaptability to salt stress and drought situations (38).

Therefore, our rationale was that PGPR inoculants could improve resistance to pathogens and salt stress in plants. The aim of this work was first, to study the ability of the four PGPR strains to improve growth and to induce systemic resistance in A. thaliana Col 0 against biotic (the leaf spot pathogen $P$. syringae DC3000) and abiotic (salt) stress. Secondly, to elucidate whether an SAdependent or an SA-independent pathway is involved in the response of the most effective strains at a biochemical level, with NahG plants and jarl mutants, and at a molecular level, with quantitative RT-PCR analysis of two transcriptional markers, the PRI gene, related to the SA-dependent pathway, and the PDF1.2 gene, related to the SA-independent pathway.

\section{MATERIALS AND METHODS}

Bacterial strains. Four PGPR strains isolated from the mycorrhizosphere of Pinus pinea L. and P. pinaster Aiton and the mycosphere of associated Lactarius deliciosus (Fries) S. F. Gray, in a previous study (1), were used: Staphylococcus sp. strain I26 (AY307362), Bacillus sp. strain L81 (AY307364), Curtobacterium sp. strain M84 (AY307369) and Arthrobacter oxidans strain BB1 (AY307363, Spanish Type Culture Collection [CECT] 7170). These bacteria showed siderophore and auxin-like compounds production, phosphate solubilization, and ACC degradation abilities (Table 1), and had demonstrated growth promotion effect on P. pinea (J. Barriuso, B. Ramos Solano, C. Santamaria, A. Daza, and J. Gutierrez Manero, unpublished data).

The leaf pathogen Pseudomonas syringae pv. tomato DC3000 was used for challenge inoculation. This strain causes bacterial speck on the model plant A. thaliana and is used to study the model system for plant-pathogen interactions (41).

Cultivation of plants. A. thaliana seeds ecotype Col 0 , transgenic NahG plants harboring the bacterial NahG gene (6), and jarl mutants (35) were sown in quartz sand watered with Hoagland solution. Two-week-old seedlings were transplanted individually to $100-\mathrm{ml}$ pots. The substrate consisted in a 12:5 ( $\mathrm{vol} / \mathrm{vol}$ ) potting soil/sand mixture, autoclaved two times for 20 min each at $121^{\circ} \mathrm{C}$, with a $24 \mathrm{~h}$ interval between each one. Then, the bacterial inoculum was mixed with the sterilized substrate when appropriate. Seedlings were cultivated in a growth chamber (Sanyo MLR-350H) with a 9-h light $\left(350 \mu \mathrm{E} \mathrm{s}^{-1} \mathrm{~m}^{-2}\right.$ at $24^{\circ} \mathrm{C}$ ) and 15 -h dark period $\left(20^{\circ} \mathrm{C}\right)$ at $70 \%$ relative humidity. Plants were watered regularly and supplied with half-strength Hoagland solution (Sigma-Aldrich) once a week throughout the experiment after transplant. All experiments followed a random block design.

Bacterial inoculation. PGPR strains were maintained at $-80^{\circ} \mathrm{C}$ in tryptic soy broth (TSB) amended with $20 \%$ glycerol. Inoculum was prepared by streaking strains from $-80^{\circ} \mathrm{C}$ onto plate count agar (PCA, Condalab, Spain) plates, incubating the plates at $28^{\circ} \mathrm{C}$ for $24 \mathrm{~h}$, and scraping bacterial cells off the plates in sterile
$10 \mathrm{mM} \mathrm{MgSO}_{4}$ buffer. The inoculation process of PGPR was as follows (Fig. 1): sterile substrate was bacterized to achieve $10^{8} \mathrm{CFU} / \mathrm{g}$. Therefore, PGPR were applied upon transplant to 2 -week-old seedlings as previously described. A second inoculum dose was applied by a soil drench $\left(10^{8} \mathrm{CFU} / \mathrm{g}\right.$ substrate $) 3$ weeks after transplant.

$P$. syringae pv. tomato DC3000 was maintained at $-80^{\circ} \mathrm{C}$ in TSB amended with glycerol. Pathogen inoculum was prepared by growing cells in TSB medium overnight, at $28^{\circ} \mathrm{C}$ under shaking. After centrifugation, bacterial cells were resuspended in $10 \mathrm{mM}$ $\mathrm{MgSO}_{4}$ buffer, and the concentration was adjusted to $10^{7} \mathrm{CFU} / \mathrm{ml}$. Inoculation procedure was as follows: plants were kept at $100 \%$ humidity for $24 \mathrm{~h}$ to ensure stomatal opening. Leaves of each plant were dipped on a $10^{7} \mathrm{CFU} / \mathrm{ml}$ solution of $P$. syringae $\mathrm{pv}$. tomato DC3000 in $10 \mathrm{mM} \mathrm{MgSO}_{4}$ buffer and kept in high humidity conditions for the following $24 \mathrm{~h}$. Nonpathogen challenged controls of all treatments were mock-inoculated with $10 \mathrm{mM}$ $\mathrm{MgSO}_{4}$ buffer and kept in parallel to observe disease progress. In the corresponding treatments, pathogen challenge was carried out 1 week after the second PGPR inoculum, which is 4 weeks after transplant.

Photosynthesis measurement. Photosynthesis was measured in three leaves of each plant in each treatment, with an FMS 2 Fluorescence Monitoring System (Hansatech, Norfolk, UK), under light conditions. Photosynthetic efficiency was measured under light conditions as the efficiency of excitation energy captured by photosystem II reaction centers, estimated by the fluorescence ratio $\left(\mathrm{F}_{\mathrm{v}} / \mathrm{F}_{\mathrm{m}}=\left(\mathrm{F}_{\mathrm{m}}-\mathrm{F}_{0}\right) / \mathrm{F}_{\mathrm{m}}\right)$, where $\mathrm{F}_{0}=$ minimum fluorescence, $\mathrm{F}_{\mathrm{m}}=$ maximum fluorescence, $\mathrm{F}_{\mathrm{v}}=$ variable fluorescence $\left(F_{m}-F_{0}\right)$, and $F_{v} / F_{m}=$ photosynthetic efficiency $(10,19,21)$.

Growth promotion assay and photosynthesis measurement in A. thaliana Col 0 plants. A. thaliana Col 0 plants were used. A split-plot design was followed. Three groups of plants were defined, with a randomized design within each group. Each group consisted on the four PGPR treatments and a noninoculated control ( $n=12$ in each treatment). One week after the second dose of PGPR, one group of plants was challenged with the pathogen (group 1), another was challenged with $\mathrm{NaCl}$ (group 2), and a non-stressed group of plants was left as a control (group 3).

The pathogen group (four PGPR treatments and the control) was inoculated with the pathogen $P$. syringae pv. tomato DC3000 as described in previously.

The salt group (four PGPR treatments and the control) was watered with a saline solution to maximum water holding capacity, in order to achieve an electrical conductivity in the substrate equivalent to that of a $60 \mathrm{mM}$ saline solution. Conductivity was determined in the $12: 5(\mathrm{vol} / \mathrm{vol})$ potting soil/sand mixture

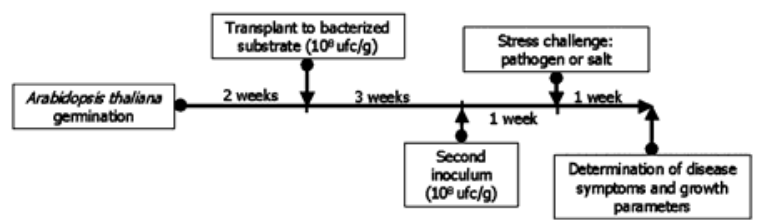

Fig. 1. Experimental design for induction of systemic resistance assay inoculation pattern.

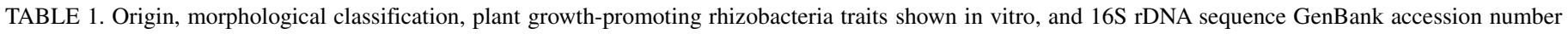
of tested bacterial strains (1)

\begin{tabular}{|c|c|c|c|c|c|c|}
\hline Strain & Morphology & Gram & Spore & Origin & Biochemical activity & Accession number \\
\hline Bacillus sp. L81 & Bacilli & + & + & Mycorrhizosphere Pinus pinea & Siderophore production & AY307364 \\
\hline Curtobacterium sp. M84 & Bacilli & + & - & Mycosphere $P$. pinea & Phosphate solubilization & AY307369 \\
\hline \multicolumn{7}{|l|}{ Arthrobacter oxidans } \\
\hline BB1 (former L62) & Bacilli & + & - & Mycorrhizosphere $P$. pinea & Auxin + siderophore production & AY307363 \\
\hline Staphylococcus sp. I 26 & Coco & + & - & Mycosphere $P$. pinaster & $\begin{array}{l}\text { Siderophore production + phosphate } \\
\text { solubilization + ACC degradation }\end{array}$ & AY307362 \\
\hline
\end{tabular}


paste, with a conductivity meter Crison (Alella, Spain). The calibration curve for substrate conductivity was obtained with increasing concentrations of $\mathrm{NaCl}$ aqueous solutions; conductivity in a $60 \mathrm{mM}$ saline solution was also determined. All measurements were done in triplicate.

One week after stress challenge, shoot fresh weight was measured in all plants and photosynthesis was measured in three leaves of each plant as described in the previously.

Induction of systemic resistance by PGPR upon pathogen challenge and salt stress. The experiment was repeated as described in the growth promotion assay with the difference that in this experiment, $50 \%$ of the plants in the pathogen group (four PGPR treatments and the control) were inoculated with the pathogen $P$. syringae pv. tomato DC3000 as described previously. Likewise, $50 \%$ of the plants in the salt group were watered with the saline solution as described in the growth promotion assay. One week after stress challenge, disease incidence and salt stress symptoms were assessed by determining the percentage of leaves with disease symptoms (chlorotic spots or wilted leaves) per plant, in stressed and in control plants.

Determination of the induction pathway: transgenic and mutant plants. The experiment of systemic resistance against the leaf pathogen $P$. syringae DC3000 was repeated with the most effective PGPR in protection to biotic and abiotic stress. BB1 and L81 were inoculated, as described previously, in A. thaliana Col 0 plants, NahG plants, and jarl mutants, following the design shown in Figure 1. In the first assay, plants were pathogen challenged and in a second assay, A. thaliana Col 0 plants, NahG plants, and jarl mutants were salt stressed as described previ-
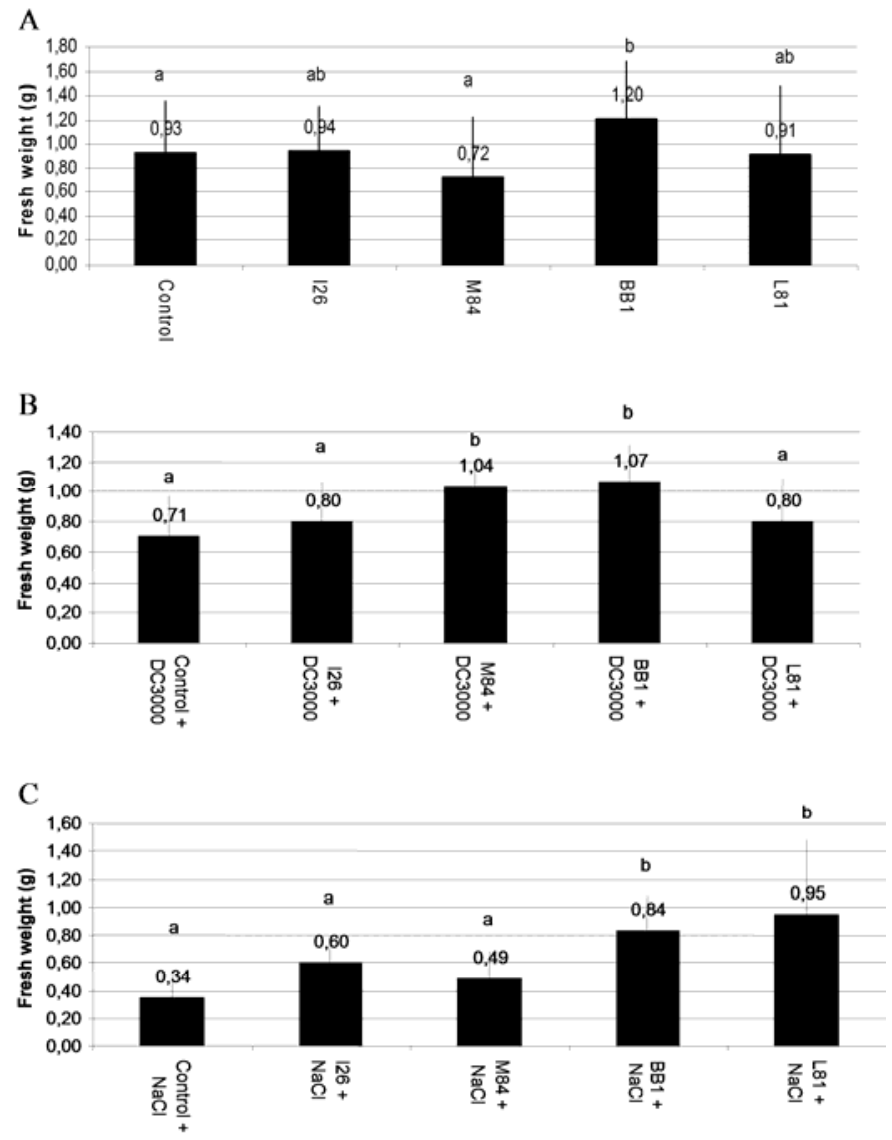

Fig. 2. Fresh weight (g) of 6-week old Arabidopsis thaliana Col 0 plants inoculated with the four plant growth-promoting rhizobacteria. A, Nonstressed, B, with biotic stress (leaf spot pathogen Pseudomonas syringae DC3000), and $\mathbf{C}$, with abiotic stress $(60 \mathrm{mM} \mathrm{NaCl})$. Bars indicate standard errors and different letters indicate the existence of significant differences according to Tuckey's test $(P<0.05)$. ously. In both cases a group of non-stressed plants was kept as control. Eighteen replicates in each treatment were used to elucidate the transduction pathway involved in the defensive response of the plants. Disease incidence was determined 1 week after stress challenge.

Determination of the induction pathway: transcriptional markers. Expression of transcriptional markers of each transduction pathway were measured in A. thaliana Col 0 plants, induced with BB1, with L81, and in non-induced controls, $24 \mathrm{~h}$ after the last PGPR bacterization (experimental design described previously). Samples were taken as follows: RNA from $A$. thaliana leaves (three replicates made of nine leaves taken from different plants) was extracted with an RNeasy Plant Mini Kit (Qiagen, CA). Five-hundred nanograms of RNA free of DNA and RNases were retrotranscribed in a $20-\mu$ l reaction: $1 \times$ RT-PCR buffer, $2.5 \mathrm{mM} \mathrm{MgCl} 2,1 \mathrm{mM}$ dNTP Blend, $10 \mathrm{U}$ of RNase inhibitor, $1.25 \mu \mathrm{M}$ Random Hexamer, and $15 \mathrm{U}$ of MultiScribe Reverse Transcriptase (Applied Biosystems, Foster City, CA). The reaction was incubated for $10 \mathrm{~min}$ at $25^{\circ} \mathrm{C}$ and $12 \mathrm{~min}$ at $42^{\circ} \mathrm{C}$ in a GeneAmp 2700 thermocycler (Applied Biosystems).

Five microliters of the retrotranscription reaction was used as a template for real time PCR with specific primers for the ACTIN1 as the housekeeping gene (ACT[PCRQ]F 5'-CGTTGCACCACCTGAAAGG-3' and ACT[PCRQ]R 5'-GGGAAGCAAGAATGGAACCA-3'), and for the transcriptional markers PR1 (PR-1qF 5'-GTCTCCGCCGTGAACATGT-3' and PR-1qR 5'-CGTGTTCGCAGCGTAGTTGT-3'), and PDF1.2 (Pdf1.2qnew2F 5'-TTGTTCTCTTTGCTGCTTTCGA-3' and Pdf1.2qnew2R 5'-TTGGCTTCTCGCACAACTTCT-3'). The reaction was performed as follows: $300 \mathrm{nM}$ each primer, $1 \times$ SYBR Green PCR Master Mix (Applied Biosystems) in a 20- $\mu$ l reaction. PCR conditions were 40 cycles, with an annealing temperature of $60^{\circ} \mathrm{C}$ in an $\mathrm{ABI}$ Prism 7700 system for quantitative PCR (Applied Biosystems).

A standard curve was performed for each primer with four serial dilutions, and data were normalized with the housekeeping gene expression. The measures were carried out with three replicates formed with nine plants in each one and the experiment was repeated twice with similar results.

Statistical analysis. To evaluate bacterial effect on growth, photosynthesis and decrease of stress incidence, unidirectional analysis of variance (ANOVA) were carried out. When differences were significant, a Tukey test $(P<0.05)$ was performed with the computer program Statgraphics plus 5.1, for Windows.

\section{RESULTS}

Growth promotion assay and photosynthesis measurement in A. thaliana Col 0 plants. The four PGPR bacterial strains Staphylococcus sp. strain I26, Bacillus sp. strain L81, Curtobacterium sp. strain M84 and Arthrobacter oxidans strain BB1 were tested in A. thaliana for their ability to enhance plant growth in normal or under stress conditions (Fig. 2A, B, and C). Only BB1 treated plants showed significant increases in fresh weight in nonstressed plants (Fig. 2A). Pathogen challenged plants inoculated with M84 and BB1 showed significantly higher values of fresh weight than the controls (Fig. 2B) while in salt stressed plants, only those inoculated with BB1 and L81 showed significantly higher values (Fig. 2C). It should be pointed out that noninoculated stressed plants showed lower weight values than nonstressed plants.

Photosynthetic values in nonstressed plants were only significantly enhanced by strain L81 (Fig. 3A). All PGPR-inoculated pathogen-stressed plants showed significantly higher values than the pathogen control (Fig. 3B); also, these values were similar to those registered in PGPR-inoculated nonstressed plants (Fig. 3A and B). On salt-stressed plants (Fig. 3C), photosynthesis values were lower than nonstressed or pathogen-stressed plants. However, salt-stressed plants treated with strains I26, BB1, and L81 
showed significantly higher values than the salt-stressed control plants.

Induction of systemic resistance by PGPR upon pathogen challenge and salt stress. Regarding the induction of systemic resistance in $A$. thaliana Col 0 plants, all strains reduced the disease index with statistical significance $(P<0.05)$ against the leaf pathogen $P$. syringae DC3000 (Fig. 4A), with reductions in the disease index of $61.2,58$, and $52.3 \%$ achieved by strains L81, M84, and BB1, respectively.

With regard to the salt stress protection in A. thaliana Col 0 plants (Fig. 4B), all strains significantly reduced chlorotic symptoms $(P<0.05)$, except for strain M84 (Fig. 4B), being the reductions in the disease index due to L81 and BB1 72.4 and $57.8 \%$, respectively.

Determination of the induction pathway: transgenic and mutant plants. Following the initial evaluation, the two strains which had performed best in protection against biotic and abiotic stress (L81 and BB1) were studied in order to elucidate the pathway elicited by each to induce systemic resistance by the means of transgenic and mutant plants. In this assay, strains L81 and BB1 significantly reduced disease symptoms in pathogen challenged (54.4 and 43.6\%, respectively) (Fig. 5) and in salt stressed jarl mutants (36.6 and 38.5\%, respectively) (Fig. 6), compared with the non-PGPR jarl mutants controls. However, NahG plants treated with L81 or BB1 showed higher disease index when challenged with the foliar leaf pathogen DC3000 (110 and $167 \%$, respectively). On the other hand, neither BB1- or L81treated NahG plants showed any significant protection against salt stress (Fig. 6). Therefore, neither of the two strains was capable of inducing systemic resistance against biotic or abiotic stress in the NahG transgenic line. The increased disease index on transgenic NahG plants is striking (Fig. 5).

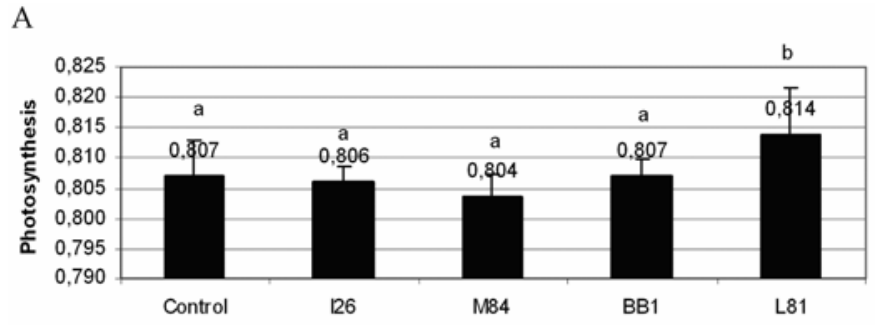

B

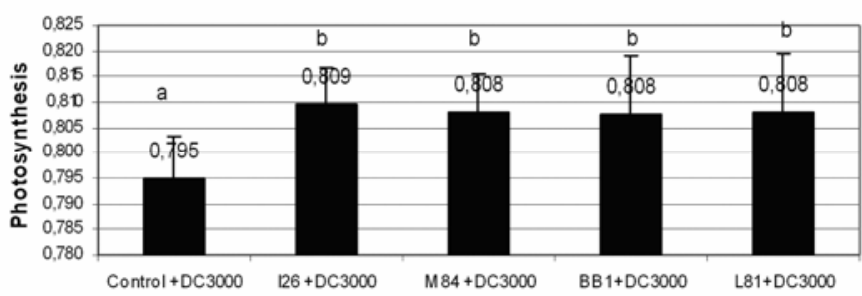

C

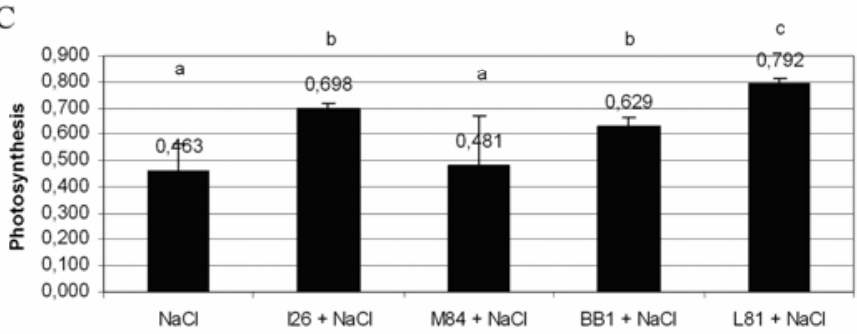

Fig. 3. Photosynthesis $\left(\mathrm{F}_{\mathrm{v}} / \mathrm{F}_{\mathrm{m}}=\left(\mathrm{F}_{\mathrm{m}}-\mathrm{F}_{0}\right) / \mathrm{F}_{\mathrm{m}}\right)$ on 6-week-old Arabidopsis thaliana Col 0 plants inoculated with the four plant growth-promoting rhizobacteria. A, Nonstressed, B, with biotic stress (leaf spot pathogen Pseudomonas syringae DC3000), and $\mathbf{C}$, with abiotic stress $(60 \mathrm{mM} \mathrm{NaCl})$. Bars indicate standard errors and different letters indicate the existence of significant differences according to Tukey's test $(P<0.05)$.
Determination of the induction pathway: transcriptional markers. In the study of transcriptional markers, the expression of two genes ( $P R I$ and $P D F 1.2$.) was measured in PGPR-induced plants and in noninduced controls. PDF1.2. was expressed at the same level in controls and in BB1- and L81-inoculated plants
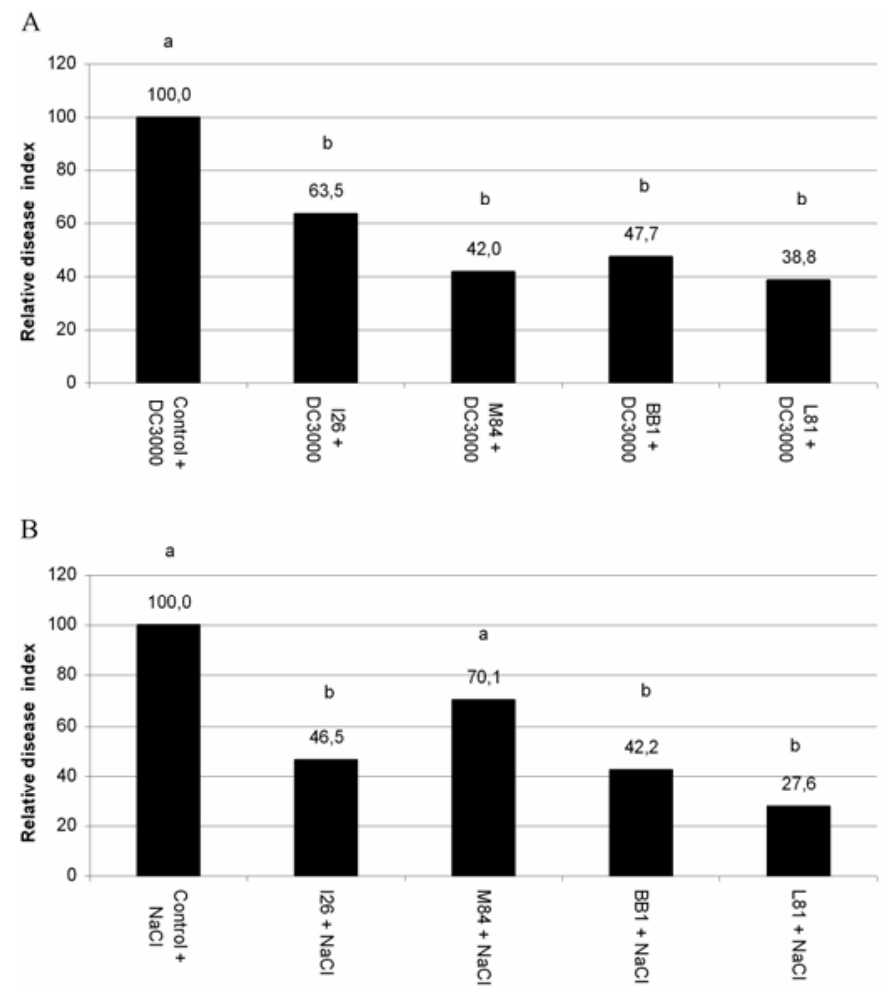

Fig. 4. Relative disease index in 6-week-old Arabidopsis thaliana Col 0 plants inoculated with the four plant growth-promoting rhizobacteria and the noninoculated control, 1 week after challenge with $\mathbf{A}$, the leaf spot pathogen Pseudomonas syringae DC3000 and $\mathbf{B}, 60 \mathrm{mM} \mathrm{NaCl}$; the control is expressed as $100 \%$ of disease incidence (disease index for control DC3000-treated plants = $50.12 \%$, disease index for control salt-stressed plants $=69.93 \%$ ). Different letters indicate the existence of significant differences according to Tukey's test $(P<0.05)$, performed separately for the pathogen-challenged and the saltstressed plants.

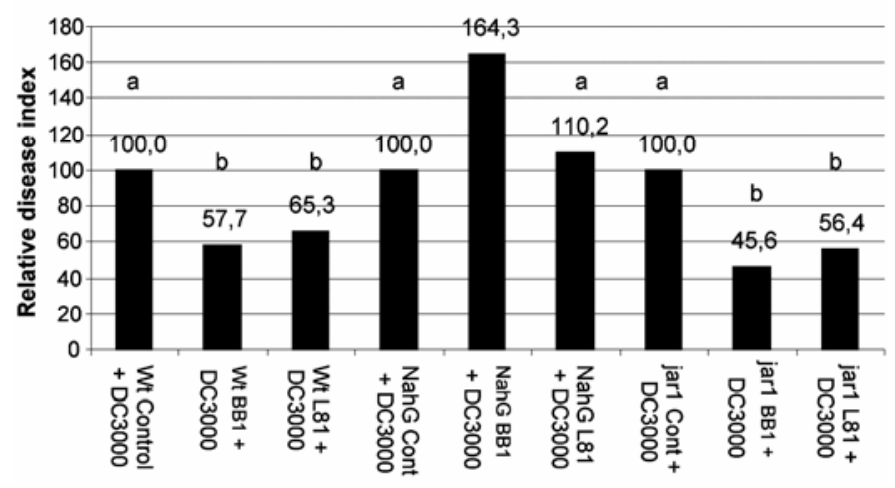

Fig. 5. Relative disease index in 6-week-old Arabidopsis thaliana Col 0, NahG transgenic line and jarl mutants inoculated with the two plant growthpromoting rhizobacteria strains, BB1 and L81, and noninoculated control, 1 week after challenge with the leaf spot pathogen Pseudomonas syringae DC 3000; the control expressed as $100 \%$ of disease incidence (disease index for control DC3000-treated plants $=45.06 \%$, disease index for NahG DC300treated plants $=37.27 \%$, and disease index for jarl DC3000-treated plants = $42,72 \%$ ). Different letters indicate the existence of significant differences according to Tukey's test $(P<0.05)$, performed separately for wild type, NahG, and Jarl plants. 
(Fig. 7) while PRI expression level in BB1-treated plants was 1.84 times the controls. There was no overexpression in L81treated plants ( 0.74 times the controls).

\section{DISCUSSION}

Search for specialized PGPR to develop inoculants to trigger defensive metabolism in plants is a challenge to improve productivity in intensive production with high pathogen incidence and in low fertility soils. In this study, four PGPR isolated in a previous work (1) were tested for their ability to promote plant growth and induce systemic resistance on A. thaliana against biotic stress (the leaf spot pathogen $P$. syringae DC3000) and abiotic stress (salt). These strains had shown putative PGPR activities in vitro (Table 1 ), and hence appeared as good candidates to induce systemic resistance.

Although all strains were able to promote growth in $P$. pinea seedlings (Barriuso et al., unpublished data) and all have shown PGPR traits in vitro (1), only BB1 significantly enhanced $A$. thaliana Col 0 growth (Fig. 2A). This may be attributed to the fact that most of the strains showed putative PGPR abilities related to plant nutrition and therefore, these strains would only be effective under nutrient stress conditions (31), which is not the case. Consistent with this argument is the ability of BB1 to release auxin-like compounds that may explain its better performance $(31,33)$. However, when PGPR-treated plants were stressed, either with biotic (the foliar pathogen $P$. syringae DC3000) or abiotic (salt) stress (Fig. 2B and C), higher weight values were found as compared to their controls; BB1- and M84-induced plants performed best under biotic stress conditions, and BB1and L81-induced plants under abiotic stress conditions. That is, PGPR had a priming effect on plants that is revealed only upon stress challenge (5). This is consistent with data from fresh weight in which PGPR-induced plants perform better than nontreated controls, either under stress or normal conditions.

The photosynthesis value is highly related to the stress level in a plant; salt stress in the roots triggers the expression of abscisic acid pathway genes (38) resulting in increased abscisic acid levels, which is in turn translocated to the leaves, where it closes the stomata, thereby decreasing the rate of photosynthesis (21). Hence, the four PGPR strains assayed improved plant health to a different extent depending on the assayed conditions, revealing different underlying mechanisms for each PGPR as indicated by the two parameters evaluated: fresh weight and photosynthesis. BB1 and L81 performed best.

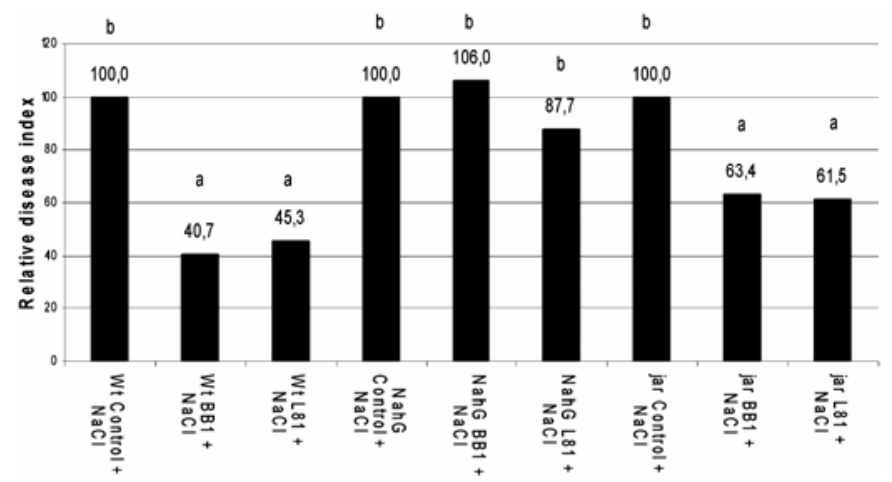

Fig. 6. Relative disease index in 6-week-old Arabidopsis thaliana $\mathrm{Col} 0$, NahG transgenic line and jarl mutants inoculated with the two plant growthpromoting rhizobacteria strains, BB1 and L81, and noninoculated control, 1 week after challenge with $60 \mathrm{mM} \mathrm{NaCl}$; the control expressed as $100 \%$ of disease incidence (disease index for control salt-stressed plants $=68.31 \%$, disease index for $\mathrm{NahG} \mathrm{NaCl-treated} \mathrm{plants}=75.65 \%$, disease index for jarl $\mathrm{NaCl}$-treated plants $=8.71 \%$ ). Different letters indicate the existence of significant differences according to Tukey's test $(P<0.05)$, performed separately for wild type, NahG, and Jarl plants.
The pathogen challenge experiment demonstrated that the induction of resistance in the plant is systemic, as PGPR are applied onto the roots and the response is detected in the shoot system, where the pathogen is applied. Interestingly, all strains that induced systemic resistance were gram positive, when this triggering capacity is usually attributed to gram negative strains because of their cell wall composition (47). However, induction of systemic resistance by gram positive strains has been previously described $(8,16)$.

Regarding the induction of systemic resistance in A. thaliana Col 0 plants against the leaf pathogen $P$. syringae DC3000, our results show that all strains assayed significantly decreased disease index when compared to the control. Also, all strains protected plants against salt stress except for strain M84 that protects but not significantly (Fig. 4). Therefore, all of them had primed plants as confirmed by the increased protection to pathogen and salt stress, confirming that priming is shown only upon stress challenge. It is striking that 3 of the 4 strains BB1, L81, and I26 were able to palliate both disease and salt stress symptoms. Although, several authors have described that the mechanisms by which PGPR diminish disease index and palliate salinity symptoms may be common, since in the process of induction of systemic resistance the coordinated activation of certain genes occurs $(4,38)$, this needs to be confirmed for each bacteria as revealed by our results in the case of M84, that protected only against biotic stress. Some of the induced proteins protect against plant pathogens (pathogenesis related proteins) (42), and others against salt stress (genes related to oxidative stress, such as cytochrome P450, glutathione reductase) (20).

It is remarkable that strain M84 was able to induce systemic resistance against the leaf pathogen $P$. syringae DC3000, while unable to protect against salt stress. This fact indicates that different pathways can be triggered upon induction, involving different sets of genes being effective against different biotic or abiotic stresses. Many authors have described the possibility that a plant's defense efficiency against a determined pathogen depends on the kind of mechanism used by the plant, and the nature of the elicitor is a key factor upon elicitation. It has been previously demonstrated with Arabidopsis genotypes affected in their responses to SA, JA, or ethylene (ET), that basal resistance against Hyalopenospora parasitica, Turnip crinkle virus and $P$. syringae is predominantly conferred by SA-dependent defense responses $(6,15,29)$, whereas basal resistance against Alternaria brassicola is mainly controlled by JA, and to a lesser extent by ET $(27,36,37)$.

The second objective of this work was to determine if the mechanism to induce systemic resistance of BB1 and L81 involves the SA-dependent or SA-independent pathway. Strains BB1 and L81 significantly reduced disease index against $P$. syringae DC3000 in wild type plants ( 42.3 and $34.8 \%$, respectively) and in jarl mutants, (54.4 and 43.6\%, respectively) (Fig. 5). The same

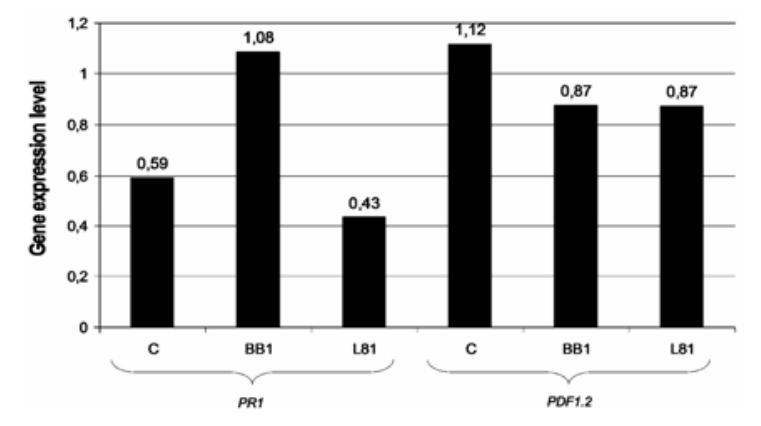

Fig. 7. Gene expression levels of the transcriptional markers PRI (SAdependent pathway) and PDF1.2 (SA-independent pathway) in Arabidopsis thaliana Col 0 plants, inoculated with the two plant growth-promoting rhizobacteria strains, BB1 and L81, and the noninoculated control. 
results were observed against salt stress; BB1 and L81 treated plants showed a significant mortality reduction in wild type plants (59.3 and 54.7\%, respectively) and in jarl mutants (36.6 and $38.5 \%$, respectively) (Fig. 6). However, in NahG plants, these strains did not cause any effect against biotic or abiotic stress and disease index was even higher than the non-PGPR-inoculated Col 0 control, probably due to the higher energy cost of the induction. BB1 induced plants may be experiencing a "detour" of energetic resources to defensive pathways. Since the subsequent signal transduction is not effective because the plant lacks the transduction signal (SA), their health is compromised when compared to noninduced plants. The same situation is evidenced for L81 but not as intense (40). Therefore, the response against biotic and abiotic stress triggered by BB1 and L81 was SA-dependent. In the case of BB1 the higher expression of PR1 gene compared to that of the control plants supports this notion (Fig. 7) and is consistent with other authors that report PGPR-induction by SA-dependent pathway and PR activation $(8,42)$. However, the increase in PR1 expression was not detected in L81 induced plants. This could be due to several reasons, among them are, (i) the moment of induction, samples for RNA were collected $24 \mathrm{~h}$ after the second PGPR inoculation, a time point when this gene may not be induced by this PGPR, (ii) the unsuitability of the transcriptional marker (any pathogenesis related protein of the family (PR3, PR5) could have another induction sequence and serve as a marker at this moment). In this sense, since PGPR are different, a different time course induction cannot be discarded. Irrespective of the hypothesis stated above, De Meyer et al. (7) demonstrated the induction of SA-dependent systemic resistance by Pseudomonas aeruginosa in tobacco in absence of detectable PR1 expression, which support data from L81.

Data presented in this study (similar expression levels of the SA-independent route transcriptional marker [PDF1.2], and the independence of JA for the induction of systemic resistance, as indicated by jarl mutants) support the notion that BB1 and L81 do not use the ET-JA transduction pathway to induce systemic resistance. On the other hand, the enhanced expression levels of PR1 in BB1-treated plants indicate that the SA-dependent route is necessary for induction of systemic resistance as suggested by other authors (42).

It may be concluded that the assayed strains are able to trigger A. thaliana systemic resistance which is effective against biotic (pathogen DC3000) and abiotic (salt) stress. In addition, it is shown that the SA-dependent pathway is involved in the response triggered by BB1. Irrespective of the pathway involved, these strains are putative PGPR to be used in intensive agricultural production processes to decrease chemical inputs, and increase crop yield in saline soils, although this capacity needs to be proven first in field trials.

\section{ACKNOWLEDGMENTS}

Founded by Ministerio de Educación y Ciencia (Spain), projects AGL 2005-07923-C05-02 and AGL 2006-13758-C05-02. We would like to thank B. Crilly for editorial help.

\section{LITERATURE CITED}

1. Barriuso, J., Pereyra, M. T., Lucas García, J. A., Megías, M., Gutiérrez Mañero, F. J., and Ramos, B. 2005. Screening for putative PGPR to improve establishment of the symbiosis Lactarius deliciosus-pinus sp. Microbiol. Ecol. 50:82-89.

2. Bowen, G. D., and Foster, R. C. 1978. Dynamics of microbial colonization of plant roots. Pages 98-101 in: Proc. Symp. Soil Microbiology and Plant Nutrition. W. J. Broughton and C. K. John, eds. Kuala Lumpur, University of Malaysia Press.

3. Bowen, G. D., and Rovira, A. D. 1999. The rhizosphere and its management to improve plant growth. Adv. Agron. 66:1-103.

4. Cheong, Y. H., Chang, H. S., Xun Wang, R. G., Zhu, T., and Luan, S. 2002. Transcriptional profiling reveals novel interactions between wound- ing, pathogen, abiotic stress, and hormonal responses in Arabidopsis. Plant Physiol. 129:661-677.

5. Conrath, U., Pieterse, C. M. J., and Mauch-Mani, B. 2002. Priming in plant-pathogen interactions. Trends Plant Sci. 7:210-216.

6. Delaney, T. P., Uknes, S., Vernooij, B., Friedrich, L., Weymann, K., Negrotto, D., Gaffney, T., Gur-Rella, M., Kessmann, H., Ward, E., and Ryals, J. 1994. A central role of salicylic acid in plant disease resistance. Science 266:1247-1250.

7. De Meyer, G., Audenaert, K., and Höfte, M. 1999. Pseudomonas aeruginosa 7NSK2-induced systemic resistance in tobacco depends on in planta salicylic acid accumulation but is not associated with PR1a expression. Eur. J. Plant Pathol. 105:513-517.

8. Domenech, J., Ramos, B., Probanza, A., Lucas García, J. A., and Gutierrez Mañero, F. J. 2007. Elicitation of systemic resistance and growth promotion of Arabidopsis thaliana by PGPR from Nicotiana glauca. A study of the putative induction pathway. Plant Soil. 290:43-50.

9. Frey-Klett, P., Pierrat, J. C., and Garbaye, J. 1997. Location and survival of Mycorrhiza helper Pseudomonas fluorescens during establishment of ectomycorrhizal symbiosis between Laccaria bicolour and Douglas fir. Appl. Environ. Microbiol. 63:139-144.

10. Gonzalez-Moro, M. B., Lacuesta, M., Iriberri, N., Munoz-Rueda, A., and Gonzalez-Murua, C. 1997. Comparative effects of PPT and AOA on photosynthesis and fluorescence chlorophyll parameters in Zea mays. J. Plant Physiol. 151:641-648.

11. Gutierrez Mañero, F. J., Acero, N., Lucas, J. A., and Probanza, A. 1996. The influence of native rhizobacteria on European alder [Alnus glutinosa (L.) Gaertn.] growth. II. Characterization of growth promoting and growth inhibiting strains. Plant Soil 182:67-74.

12. Gutierrez Mañero, F. J., Ramos, B., Lucas García, J. A., Probanza, A., and Barrientos, M. L. 2003. Systemic induction of the biosynthesis of terpenic compounds in D. lanata. J. Plant Physiol. 160:105-113.

13. Gutierrez Mañero, F. J., Ramos Solano, B., Probanza, A., Mehouachi, J., Tadeo, F. R., and Talon, M. 2001. The plant growth-promoting rhizobacteria Bacillus pumilus and Bacillus licheniformis produce high amounts of physiologically active gibberellins. Physiol. Plantarum. 111:1-7.

14. Heck, S., Grau, T., Buchala, A., Metraux, J. P., and Nawrath, C. 2003. Genetic evidence that expression of NahG modifies defense pathways independent of salicylic acid biosynthesis in the Arabidopsis-Pseudomonas syringae pv. tomato interaction. Plant J. 36:342-352.

15. Kachroo, P., Yoshioka, K., Shah, J., Dooner, K. D., and Klessig, D. F. 2000. Resistance to turnip crinkle virus in Arabidopsis is regulated by two host genes and is salicylic acid dependent but NPR1, ethylene and jasmonate independent. Plant Cell. 12:677-690.

16. Kloepper, J. W., Ryu, C. M., and Zhang, S. A. 2004. Induced systemic resistance and promotion of plant growth by Bacillus spp. Phytopathology 94:1259-1266

17. Kloepper, J. W., Scrhoth, M. N., and Miller, T. D. 1980. Effects of rhizosphere colonization by plant growth-promoting rhizobacteria on potato plant development and yield. Phytopathology 70:1078-1082.

18. Knoester, M., Pieterse, C. M. J., Bol, J. F., and Van Loon, L. C. 1999. Systemic resistance in Arabidopsis induced by rhizobacteria requires ethylene-dependent signaling at the site of application. Mol. PlantMicrobe Interact. 12:720-727.

19. Krause, G. H., and Weis, E. 1984. Chlorophyll fluorescence as a tool in plant physiology. II. Interpretation of fluorescence signals. Photosynth. Res. 5:139-157.

20. Kreps, J. A., Wu, Y. J., Chang, H. S., Zhu, T., Wang, X., and Harper, J. F. 2002. Transcriptome changes for Arabidopsis in response to salt, osmotic, and cold stress. Plant Physiol. 130:2129-2141.

21. Lambers, H., Chapin, F. S., and Pons, T. L. 1998. Plant Physiological Ecology. Springer-Verlag, New York.

22. Lawton, K. A., Friedrich, L., Hunt, M., Weymann, K., Delaney, T., Kessmann, H., Staub, T., and Ryals, J. 1996. Benzothiadiazole induces disease resistance in Arabidopsis by activation of the systemic acquired resistance signal transduction pathway. Plant J. 10:71-82.

23. Lawton, K. A., Weymann, K., Friedrich, L., Vernooij, B., Uknes, S., and Ryals, J. 1995. Systemic acquired resistance in Arabidopsis requires salicylic acid but not ethylene. Mol. Plant-Microbe Interact. 8:863-870.

24. Lucas García, J. A., Probanza, A., Ramos, B., Barrientos, M. L., and Gutiérrez Mañero, F. J. 2001. Genetic variability of rhizobacteria from wild populations of four lupinus species based on PCR-RAPDs as a tool to select potential PGPR. J. Plant Nutr. Soil Sci. 164:1-7.

25. Lynch, J. M. 1990. The Rhizosphere. Wiley-Interscience, Chichester, England.

26. Marilley, L., and Aragno, M. 1999. Phylogenetic diversity of bacterial communities differing in degree of proximity of Lolium perenne and Trifolium repens roots. Appl. Soil Ecol. 13:127-136.

27. O'Donnell, P. J., Jones, J. B., Antoine, F. R., Ciardi, J., and Klee, H. J. 2001. Ethylene dependent salicylic acid regulates an expanded cell death response to a plant pathogen. Plant J. 25:315-323. 
28. Pieterse, C. M. J., Van Pelt, J. A., Ton, J., Parchmann, S., Mueller, M., Buchala, A. J., Metraux, J., and Van Loon, L. C. 2000. Rhizobacteriamediated induced systemic resistance (ISR) in Arabidopsis requires sensibility to jasmonate and ethylene but is not accompanied by an increase in their production. Physiol. Mol. Plant P. 57:123-134.

29. Pieterse, C. M. J., Van Wees, S. C. M., Hoffland, E., Van Pelt, J. A., and Van Loon, L. C. 1996. Arabidopsis induced by biocontrol bacteria is independent of salicylic acid accumulation and pathogenesis gene expression. Plant Cell. 8:1225-1237.

30. Pieterse, C. M. J., Van Wees, S. C. M., Van Pelt, J. A., Knoester, M., Laan, R., Gerrits, H., Weisbeek, P. J., and van Loon, L. C. 1998. A novel signaling pathway controlling induced systemic resistance in Arabidopsis. Plant Cell. 10:1571-1580.

31. Ramos Solano, B., Pereyra de la Iglesia, M. T., Probanza, A., Lucas García, J. A., Megías, M., and Gutierrez Mañero, F. J. 2006. Screening for PGPR to improve growth of Cistus ladanifer seedlings for reforestation of degraded Mediterranean ecosystems. Plant Soil 289:59-68.

32. Ryals, J. A., Neuenschwander, U. H., Willits, M. G., Molina, A., Steiner, H. Y., and Hunt, M. D. 1996. Systemic acquired resistance. Plant Cell. 8:1809-1819.

33. Rainey, P. B. 1999. Adaptation of Pseudomonas fluorescens to the plant rhizosphere. Environ. Microbiol. 1:243-257.

34. Schenk, P. M., Kazan, K., Wilson, I., Anderson, J. P., Richmond, T., Sommerville, S. C., and Manners, J. M. 2000. Coordinate plant defense response in Arabidopsis revealed by microarray analysis. P. Natl. Acad. Sci. USA 97:11655-11660.

35. Staswick, P. E., Yuen, G. Y., and Lehman, C. C. 1992. Methyl jasmonate inhibition of root growth and induction of a leaf protein are decreased in an Arabidopsis thaliana mutant. Proc. Natl. Acad. Sci. USA 89:68376840 .

36. Thomma, B. H. P. J., Erggemont, K., Pennicks, I. A. M. A., Mauch Mani, B., Vogelsang, R., Cammue, B. P. A., and Broekaert, W. F. 1998. Separate jasmonate-dependent and salicylate-dependent defense-response pathways in Arabidopsis are essential for resistance to distinct microbial pathogens. Proc. Natl. Acad. Sci. USA 95:15107-15111.

37. Thomma, B. H. P. J., Erggemont, K., Tierens, F. M. J., and Broekaert, W. F. 1999. Requirement of functional ethylene-insensitive 3 gene for efficient resistance of Arabidopsis to infection by Botrytis cinerea. Plant
Physiol. 121:1093-1101.

38. Timmusk, S., and Wagner, E. G. H. 1999. The plant-growthpromoting rhizobacterium Paenibacillus polymyxa induces changes in Arabidopsis thaliana gene expression: A possible connection between biotic and abiotic stress responses. Mol. Plant-Microbe Interact. 12:951959.

39. Uknes, S., Winter, A. M., Delaney, T. P., Vernooij, B., Morse, A., Friedrich, L., Nye, G., Potter, S., Ward, E., and Ryals, J. 1993. Biological induction of systemic acquired resistance in Arabidopsis. Mol. PlantMicrobe Interact. 6:692-698.

40. van Hulten, M., Pelser, M., van Loon, L. C., Pieterse, C. M. J., and Ton, J. 2006. Cost and benefits of priming for defense in Arabidopsis. Proc. Natl. Acad. Sci. USA 103:5602-5607.

41. van Loon, L. C., Bakker, P. A. H. M., and Pieterse, C. M. J. 1998. Systemic resistance induced by rhizosphere bacteria. Annu. Rev. Phytopathol. 36:453-483.

42. van Peer, R., Niemann, G. J., and Schippers, B. 1991. Induced resistance and phytoalexin accumulation in biological control of Fusarium wilt of carnation by Pseudomonas sp. strain WCS417r. Phytopathology 91:728734

43. van Wees, S. C. M., De Swart, E. A. M., van Pelt, J. A., van Loon, L. C., and Pieterse, C. M. J. 2000. Enhancement of induced disease resistance by simultaneous activation of salicylate- and jasmonate-dependent defense pathways in Arabidopsis thaliana. Proc. Natl. Acad. Sci. USA 97:8711-8716.

44. van Wees, S. C. M., Pieterse, C. M. J., Trijssenaar, A., Vant Westende, Y. A. M., Hartog, F., and van Loon, L. C. 1997. Differential induction of systemic resistance in Arabidopsis by biocontrol bacteria. Mol. PlantMicrobe Interact. 10:716-724.

45. Vessey, J. K. 2003. Plant growth promoting rhizobacteria as biofertilizers. Plant Soil 255:571-586.

46. Verhagen, B. W. M, Glazebrook, J., Zhu, T., Chang, H .S., van Loon, L. C., and Pieterse, C. M. J. 2004. The transcriptome of rhizobacteriainduced systemic resistance in Arabidopsis. Mol. Plant-Microbe Interact. 17:895-908

47. Yamaguchi, T., Ito, Y., and Shibuya, N. 2000. Oligosaccharide elicitors and their receptors for plant defense responses. Trends Glycosci. Glyc. 12:113-120. 